\title{
The Role of the Federal Government in Supporting Domestic Disaster Preparedness, Response, and Recovery
}

\section{Andrew L. Garrett, MD, MPH, FAEMS, FAAP}

\section{Address}

The George Washington University School of Medicine and Health Sciences, 2600 Virginia Avenue NW, Suite T-100, Washington, DC, 20037, USA

Email: andrew_garrett@gwu.edu

Published online: 4 June 2019

(C) The Author(s) 2019

This article is part of the Topical Collection on Disaster Medicine

Keywords Federal $\cdot$ Government $\cdot$ Disaster $\cdot$ Preparedness $\cdot$ Response $\cdot$ Children

\section{Abstract}

Purpose of review A series of serious domestic catastrophes in the new millennium brought attention to many of the specific vulnerabilities of children in disaster. Both on its own initiative and steered by advisory bodies, since then, the federal government has taken an increasingly proactive role in supporting the needs of children in the preparedness for, response to, and recovery from disasters. This report will provide the pediatric provider with an understanding of the federal authorities, policies, and tools that exist to support communities before, during, and after the impact of disaster, with a special emphasis on pediatric preparedness. It will also provide the reader with potential options for becoming more involved in disaster preparedness and response.

Recent findings The goal of improving the care of children in disaster is being approached through a national-level whole community model of preparedness that considers children of all abilities and needs, as well as the places where they spend their time as integral components of a prepared and resilient community.

Summary The federal government is a critical partner along with state, local, and regional stakeholders to improve the care of children impacted by disaster. 


\section{Introduction}

Children under 18 years old comprise about $22 \%$ of the US population, representing a cohort which is at disproportionate risk during and after a disaster based on the biological, psychological, and sociological vulnerabilities of infants, children, and adolescents (Table 1) [13]. The $9 / 11$ terror attacks quickly followed by the 2001 domestic anthrax attack and then the catastrophic impact of the 2005 Atlantic hurricane season exposed these vulnerabilities on both the public and political stage as a 7-month-old child became one of the earliest and most visible victims of the biological attack, and as over 160,000 children were displaced from their homes during Hurricane Katrina [4]. Terror attacks both foiled and successful, such as the 2004 Beslan school siege in Russia where over half of the 330 casualties were children, and an Al-Qaida statement from 2002 ruling that American children were in play as potential targets of future attacks compounded the urgency to identify and mitigate shortfalls in the care of children during and after a disaster [5]. The public feels that this is an important issue-a 2010 national poll found that $75 \%$ of adults felt that children should be prioritized for medical care during disasters, with $92 \%$ believing that children should have parity in the access to the same lifesaving treatments available to adults in a disaster [3].
As the federal government appraised the scope of the exposed shortfalls in the care of children in disaster, one of the most significant initial actions it took was Congress convening the National Commission on Children and Disaster (NCCD) in 2007 [6]. The NCCD explored issues related to children and made recommendations to the President in 2010 which focused on Management and Recovery, Mental Health, Child Physical Health and Trauma, Prehospital Care and Transport, Disaster Case Management, Education, Welfare and Juvenile Justice, Sheltering, Housing, and Evacuation. The NCCD interim report stated in 2008 that there were, "serious deficiencies in each functional area, where children were more often an afterthought than a priority," [2] a sobering assessment that represented a starting point for improvements in how our nation would care for those most at risk during a disaster and what the federal government's role would be in those efforts. While many of the shortfalls outlined in the NCCD report remain incompletely resolved in 2019, significant progress has been made by many federal departments and agencies. Perhaps the most notable milestone in the last decade is the recognition across the whole government that caring for children in disasters is an important priority for the public health security of our nation.

\section{Federal departments work to improve the care of children in disasters}

The Federal Emergency Management Agency (FEMA) is a component of the Department of Homeland Security (DHS) and has the primary responsibility of coordinating national-level emergency management for the federal government's role in preparing for, responding to, and recovering from domestic disasters, a process which will be described below. FEMA made the pivotal decision in 2011 to realign the paradigm under which it undertakes its mission of emergency management-adopting a whole community approach to their efforts-a move which helped support the inclusion of children and other groups of people with special access and functional needs during a disaster and ensuring that they were not deprioritized in planning and response activities [7]. FEMA established a senior level intra-agency Children's Working Group in 2009 to synergize the Agency's efforts around pediatric preparedness and response planning. Achievements have included the integration of age-appropriate supplies for infants and children into emergency preparedness plans, the inclusion of pediatric equipment on 


\section{Table 1. Using the bio-psycho-social model to describe the vulnerabilities of children in disasters, including terrorism}

\section{Biological}

When encountering the hazards in a disaster, the physical proportions of children may predispose to more serious injury compared to adults:

- Relatively large head

- Less protected abdominal organs

- Less protective fat and relatively large surface to body ratio increases susceptibility to hypothermia

Physiologic issues that may increase the risk of injury in a disaster:

- Higher minute ventilation rate may increase risk of inhalation of hazardous substances and increased insensible losses

- Increased permeability of the blood-brain barrier

- Rapid growth and development at the cellular level

- Children require size-appropriate medical equipment and therapies for prevention, treatment, and resuscitation which may be difficult to source

- More permeable integument and larger surface to body ratio may increase risk from toxins or chemicals

Using different physiologic parameters in the disaster triage of pediatric patients alongside adults may be challenging for providers, given a lack of tools, training, and experience

Children may be technically challenging for providers to assess and treat, especially for those without pediatrics experience:

- Weight-based dosing and formulary challenges such as lack of availability of pediatric-suitable countermeasures

- Sick or injured pediatric patients may be stressful for providers

- Decontamination and sheltering of children may pose serious logistics challenges at non-pediatric facilities

- With a self-reported prevalence of about $13 \%$, children with special access and functional needs are often difficult for unfamiliar providers to assess and care for

Psychological

Children may take unpredictable actions in a disaster which may put them at increased risk:

- Evacuating away from a threat may be non-intuitive for young children

Children may present with unfamiliar symptomology from behavioral health issues and this may occur on a timeline that is unfamiliar to both caregivers and providers:

- Children may experience aspects of regressive or aggressive behavior, anxiety, depression, and/or sleep disturbances

- Somatic complaints may occur, such as headache, abdominal or chest pain

Social

The day-to-day normal activities of children can pose challenges to preparedness, which may put them at disproportionate risk during a disaster:

- Children require continuous care and supervision, and this dependence on others may increase their vulnerability in a disaster if separation occurs

- Young children are often cohorted (e.g., school, camp, daycare, and hospital), which may make supervision in a disaster problematic and may represent a "soft target" for criminal or terrorist activity

- Young children operate lower to the ground and have frequent hand-to-mouth activity which may place them in proximity to disaster-related hazards

Children's tertiary facilities are often centralized in a geographic region, which can represent a single point of failure in a disaster 
ambulances, advancing capabilities for the appropriate emotional and mental health support for children and families, and establishing resources to support the expeditious and safe reunification of children who have been separated from their caregivers in the aftermath of a disaster. FEMA has also championed the role of youth leaders in advancing community and family preparedness through their innovative Youth Preparedness Program, including the release of educational and guidance tools available to the public [8].

The Department of Health and Human Services (HHS) established its intra-agency Children's HHS Interagency Leadership on Disasters (CHILD) Working Group in 2010 to "integrate the needs of children across all HHS disaster planning activities and operations." [9] Since then, the Department has established a national multi-lingual Disaster Distress Helpline (1-800-985-5990) to provide emergency assistance to those with emotional distress related to a disaster [10]. The HHS Office of the Assistant Secretary for Preparedness and Response (ASPR) coordinates the public health and medical response to disasters for the federal government, which includes operational oversight of the National Disaster Medical System (NDMS) and the U.S. Public Health Service (USPHS)-federal assets which provide direct clinical services to the public after major disasters. After the NCCD report in 2010, NDMS increased the relative percentage of its provider training that focuses on the care of children and families-including the use of simulations in full-context field training for response teams and training in Psychological First Aid to enable responders to provide initial stabilizing care in the field. ASPR hosts the Technical Resources, Assistance Center, and Information Exchange (TRACIE) website which was created in 2016 to meet the information and technical assistance needs of healthcare personnel and emergency managers [11]. The Biomedical Advanced Research and Development Authority (BARDA) is housed in ASPR and leads the government's efforts to provide an effective medical countermeasure strategy from disasters both natural and intentional. ASPR is also home to the Hospital Preparedness Program (HPP), which provides direct federal support for the advancement of regional health care coalitions [12]. In 2013, HHS established a National Advisory Committee on Children and Disasters (NACCD) with the purpose of establishing a group of subject matter experts from both the private and public sectors to advise the HHS Secretary on issues related to children in disasters [13]. The Centers for Disease Control and Prevention (CDC), an operational division of HHS, established its Children's Preparedness Unit (CPU) in 2011 to advance the agency-wide coordination of planning and response efforts for children during public health emergencies. The Strategic National Stockpile (SNS) is a component of HHS that can quickly deliver emergency medicines, vaccines, and supplies anywhere in the USA, and which also supports caches of pre-deployed chemical antidotes that provide access to $90 \%$ of

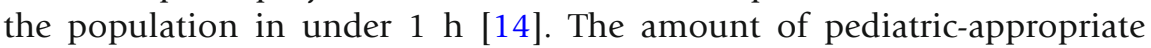
supplies in the SNS has improved in the last decade, but challenges remain given approval and labeling restrictions for many of the medical countermeasures in the stockpile [15]. 


\section{The federal coordination of disasters: understanding the alphabet soup}

It is important to recognize that the comprehensive emergency management of most disasters typically begins and ends at the local, regional, or state level. For most disasters, the federal government will not be requested to assist or it may be engaged after the fact for specific types of limited assistance, often financial. In complex or catastrophic events that exceed the capabilities of the local, regional, or state authorities to effectively manage the urgent needs of their communities, there may be a request for federal assistance that includes but is not limited to public health and medical teams and support for sheltering, evacuation, or search and rescue. These larger disaster responses also typically include assistance to both individuals (e.g., case management, legal services, nutrition assistance, and crisis counseling) and to public agencies (debris removal, utilities repair, and road and airport repair, etc.).

When the federal government is requested on to engage, DHS and HHS play perhaps the most visible roles in the response to major domestic disaster. The White House and numerous other departments are typically also involved in the whole of government response. This may include the Environmental Protection Agency, the Department of Defense, the Army Corps of Engineers, the Federal Bureau of Investigation, and many others. Collaborating with the federal departments and agencies in providing national-level services to children and families are many critical non-federal organizations such as the American Red Cross and the National Center for Missing and Exploited Children (NCMEC).

Much of the authority for the federal government to deliver disaster assistance to communities lies with the Robert T. Stafford Disaster Relief and Emergency Assistance Act (Stafford Act). A Stafford Act declaration is initiated via a request from the Governor of an impacted state or territory and is reviewed and approved by the President. A Stafford Act declaration enables and funds FEMA to assume its overall coordination role for the national-level response. Two types of declarations are possible. Incidents that are smaller in scope but which still require federal assistance totaling less than 5 million dollars are termed Emergency Declarations and authorize FEMA to coordinate a limited scope of individual and public assistance support. A Major Disaster Declaration is for disasters that are larger in terms of the scope of federal assistance and funding support that will be required by the impacted jurisdictions [16]. Beyond the Stafford Act, the legal authorities that authorize a federal disaster response are fairly complex-there are numerous laws and policies that each pertain to a specific capability. One of the most recognizable is the Emergency Management Assistance Compact (EMAC) which empowers the state-to-state mutual aid of disaster response assets such as medical teams. All states have joined the compact, which helps reduce the red tape that is often seen around the crossjurisdictional deployment of assets, especially with regard to licensure, liability, workers' compensation, and reimbursement [17].

To effectively coordinate this type of complex incident, the federal government has established policies that outline the strategy that the federal 
government and other state, local, tribal, and territorial officials can use to interact during different phases of disasters, from long before an event occurs, during response, and in the ensuing long-term recovery phase that takes place after a catastrophic event. The principal guidance for this effort comes from the National Response Framework (NRF), a policy document which "describes the principles, roles, and responsibilities, and coordinating structures for delivering the core capabilities required to respond to an incident and further describes how response efforts integrate with those of the other mission areas." [18] The NRF leverages longstanding principles and best practices in emergency management that are familiar to officials at all levels, such as the Incident Command System (ICS) approach to incident management and the National Incident Management System (NIMS) as described below. To coordinate the massive effort of a national-level response, FEMA utilizes the National Response Coordination Center (NRCC) in Washington, D.C.

As prescribed by the NRF, the federal government and most other response entities interact using NIMS concepts to ensure consistency in the coordination of disaster response. NIMS was first published by DHS in 2004 and most recently updated in 2018 with the intent of providing a common operating system to improve the management of response assets from across jurisdictions, including those from other states and the federal government. The foundation of NIMS is a flexible and scalable framework using standardized best-practice tools in order to support multi-agency coordination [19]. Having all response activities utilizing a consistent approach to incident management is critical for major incidents such as wildland fires, large natural disasters, and complex terrorist incidents where a lack of effective oversight could lead to additional injuries, casualties, or cost.

Because certain aspects of disaster response are consistently specialized and significant in scope and scale, the NRF also includes additional structure in the form of the Emergency Support Function (ESF) Annexes. ESFs are organized functionally and serve to group like capabilities from across the governmental and private sectors. There are 15 ESF annexes, but the two that are most pertinent to the care of children in disaster are ESF 8-Public Health and Medical Services and ESF 6-Mass Care, Housing, and Human Services. If FEMA and its NRCC is the hub of the overall federal disaster response, the ESFs represent spokes, each with its own lead federal agency and its own operations center to collaborate with a wide range of stakeholders both public and private to ensure a common operating picture, and the coordination of effort. There is continuous coordination between the NRCC and the lead agencies for the ESFs. In a federally declared major disaster, FEMA has the responsibility for delegating mission assignments to the ESF groups, with any necessary funding. Outside of a Stafford Act declaration, some agencies under each ESF have the independent authority to perform disaster preparedness, response, and recovery functions.

For ESF-6, FEMA is the lead federal agency along with the American Red Cross, a non-governmental organization. In collaboration with a range of other federal agencies and dozens of other National Voluntary Organizations Active in Disaster (NVOAD), this ESF supports four major functions: (1) Mass Care, which includes feeding and sheltering operations and (2) Emergency Assistance such as the management of donated goods, family reunification, and support to regular and medical shelters. It also includes (3) Housing, including loan assistance for 
repairs and the provision of temporary housing, and (4) Human Services such as property replacement, crisis counseling, disaster loans, and support to individuals with special access and functional needs. As an example of the whole community efforts that are taking place-FEMA, the American Red Cross, NCMEC, the American Academy of Pediatrics (AAP), and several private institutions including Massachusetts General Hospital collaborated to produce Reunification Following Disasters: a Planning Tool for Healthcare Facilities [20] which is available online.

For ESF-8, HHS is the lead federal agency. During response and recovery activities, HHS coordinates the overall federal ESF- 8 response through the Secretary's Operations Center in Washington, DC, in collaboration with numerous other federal agencies including the Department of Defense, local and state officials, and private sector resources such as the American Red Cross, the Kidney Community Emergency Response organization, and many others [21]. ESF-8 resources that are available to the states include the deployment of federal medical, mass fatality, public health, and veterinary teams through the NDMS, CDC, USPHS, or others to support a request from an impacted state. In most cases, any federal assistance which is deployed to a state must be done at the request of that state, and there may be a cost share to receive certain services. The Secretary of HHS has broad authority to declare a Public Health Emergency and to take actions authorized under a suite of special authorities: the Public Health Service Act, the Public Readiness and Emergency Protections (PREP) Act, the Pandemic and all-Hazards Preparedness Act (PAHPA), and the Social Securities Act. These allow the Secretary to expend federal money, deploy federal medical and public health resources, and to modify certain federal regulations in order to facilitate the prompt care of those who are impacted by the disaster. This may include a waiver of sanctions for violations of patient privacy or the reassignment of HHS employees to support the response [22]. It could also include the waiving of liability for those involved in the manufacture, distribution, and administration of medical countermeasures to a chemical, biological, or radiological threat. [17] Other divisions of HHS, such as the Food and Drug Administration (FDA), the Substance and Mental Health Services Administration (SAMHSA), and the National Institutes of Health (NIH) support the whole government response by ensuring that pediatric patients and providers have access to necessary medical treatments and specialized medical and mental health care information.

While the NRF provides the structure for a coordinated whole government response to disasters, it does not provide a structure for what the federal government's role is along with the rest of the preparedness community in protecting the nation from terrorist events, preventing and mitigating disasters, and in the longer-term recovery after a response winds down. Each of these parts of the disaster lifecycle has its own framework document produced by FEMA which feeds in to an overarching strategy called the National Preparedness Goal: $[23,24,25 \bullet \bullet, 26,27]$

The National Preparedness Goal: A secure and resilient Nation with the capabilities required across the whole community to prevent, protect against, mitigate, respond to, and recover from the threats and hazards that pose the greatest risk [28]. 
Although the federal government can capably serve in the overall coordination role for a national level disaster, history has proven time and time again that the federal government alone does not possess adequate resources to meet the comprehensive needs of the public following a catastrophic disaster on the order of a Hurricane Katrina, Superstorm Sandy, or Hurricane Maria which devastated Puerto Rico in 2017. And although each of these disasters was among the worst we have experienced in recent history, there remain potential disasters that would dwarf even these events-such as a pandemic, nuclear detonation, or massive seismic event or tsunami directly impacting the USA. For this reason, most of the above-mentioned laws and policies identify how the federal government will be a part of the response as a partner along with other state, local, tribal, and territorial governments, volunteer groups, businesses and corporations, non-governmental organizations, and the public itself. The bottom line is simply that without engaged stakeholders in disaster preparedness at every level in our communities, our nation may not be able to meet the public's needs when a catastrophic disaster occurs.

Medical providers at all levels are a critical part of the whole community that is responsible for the adequate care of children in a disaster. There are many ways to engage in disaster preparedness-each of these options increases our national public health security and with it, the ability of the entire response community from local to federal to better care for those most vulnerable in a disaster-our children.

As an important note, any responder who chooses to perform clinical work during a disaster that is outside of their normal work contract and scope of practice should make sure to verify that they are adequately licensed to function where they are working, and that they are properly protected against liability, injury, death, and disability [29].

1. Taking personal and family preparedness seriously: In the USA, despite a recurrent pattern of major disasters affecting the USA in the new millennium, less than $40 \%$ of Americans have developed any kind of personal or family disaster plan, a number which has not increased much in the past decade and a half despite aggressive advocacy from public health officials [30]. Having a family disaster plan is a prerequisite for becoming more involved in disaster response work at any level, and it does not need to be extensive or expensive. A great resource to get started is www.READY.gov, which is FEMA's website that provides recommendations, checklists, and guidance for those who are interested in ensuring their family's safety during the next disaster.

2. Become engaged in your employer's disaster preparedness efforts: Clinical providers with experience in pediatric medicine are important assets in a disaster, but they can be even more valuable in systematic pediatric preparedness planning. Even in 2019, children remain at a disproportionate disadvantage in a disaster. Clinics, hospitals, and medical centers of all types-both general and pediatric - are critical assets in a disaster, and must function effectively under both adverse conditions and a surge in patient volume. Experience has shown that hospitals proximal to a disaster will 
receive the sickest patients, often even if there are community plans in place to move pediatric patients to a regional specialty facility. Hospitals should be ready to receive a surge which includes $10-20 \%$ pediatric patients after a mass casualty incident or disaster, even if they are not typically thought of a pediatric receiving facility. For most medical facilities, having a preparedness plan that includes exercises is mandatory to participate in the Medicare and Medicaid programs under their 2016 Emergency Preparedness Rule [31 •], and most hospital administrations would welcome the input of a motivated pediatric provider in both the planning process, and to help the facility respond to a disaster that includes children.

3. Volunteer to help locally: Many communities have opportunities for clinical personnel to volunteer to assist during and after a disaster. One of the most recognized is the Medical Reserve Corps (MRC), with almost 200,000 volunteers organized into 900 locally based units. MRC clinicians may help staff a medical shelter, dispense countermeasures after a disaster, or perform a wide range of other roles to directly help their community. Find an MRC unit close to you at https://mrc.hhs.gov/FindMRC. Also, consider joining a local volunteer fire department or community EMS service. Across the USA, ensuring the day-to-day safety of communities is accomplished because of volunteers-with $85 \%$ of fire and emergency services departments being all or mostly comprised of volunteer staff [32]. The American Red Cross and other local volunteer organizations that assist with disaster sheltering and medical care may also be available as well. Lastly, the Emergency System for the Advanced Registration of Volunteer Health Professionals (ESAR-VHP) is a federal program administered at the state level for the purpose of standardizing and validating the credentials of providers who would like to serve their communities during a disaster. More information is available at https://www.phe.gov/esarvhp/pages/registration.aspx.

4. Join a state or federal disaster response team: Many states have established medical response teams that can offer qualified clinical and support personnel an opportunity to deliver care to communities impacted by a disaster or public health emergency. Often these teams can be deployed across state borders using EMAC, which is described above. At the federal level, the National Disaster Medical System (NDMS) has responded to hundreds of disasters in the USA and internationally to provide medical, veterinary, and mass fatality support to impacted communities. NDMS responders are hired by HHS as intermittent federal employees, and are by statute are provided compensation, workers' compensation, and liability coverage [33].

5. Volunteer with a non-governmental organization: There are many nationallevel NGOs that may provide an opportunity for a pediatric clinician to deploy either domestically or internationally to both disasters and areas involved in humanitarian crisis. Examples include Team Rubicon and the International Medical Corps (IMC), but there are many that work in close collaboration with the states and the federal government during disaster response in the USA $[34,35]$. Additionally, the AAP is a professional organization actively involved in advocating for the improvement of how children are cared for in disasters, and there may be opportunities to support these efforts at the chapter or national level [36•]. 


\section{Compliance with Ethical Standards}

\section{Conflict of Interest}

Andrew Garrett is an intermittent disaster response employee with the U.S. Department of Health and Human Services. He developed this content in his personal capacity. The views expressed are his own and do not necessarily represent the opinions of the Department or the United States Government.

\section{Human and Animal Rights and Informed Consent}

This article does not contain any studies with human or animal subjects performed by any of the authors.

Open Access This article is distributed under the terms of the Creative Commons Attribution 4.0 International License (http://creativecommons.org/licenses/by/4.0/), which permits unrestricted use, distribution, and reproduction in any medium, provided you give appropriate credit to the original author(s) and the source, provide a link to the Creative Commons license, and indicate if changes were made.

\section{References}

Papers of particular interest, published recently, have been highlighted as:

- Of importance

$\bullet \quad$ Of major importance

1. Federal Interagency Forum on Child and Family Statistics. Childstats.gov - Home. 2018. https://www. childstats.gov/index.asp. Accessed 27 Dec. 2018.

2. Agency for Healthcare Research and Quality. National Commission on Children and Disasters 2010 report to the president and congress. 2010. http://archive.ahrq.gov/ prep/nccdreport/nccdreport.pdf. Accessed 27 Dec. 2018.

3. American Academy of Pediatrics. Ensuring the health of children in disasters. 2015. http://pediatrics. aappublications.org/content/pediatrics/early/2015/ 10/13/peds.2015-3112.full.pdf. Accessed 1 Jan. 2019.

4. Redlener I, Abramson D, Stehling-Ariza T and Fuller E. The legacy of Katrina's children: estimating the numbers of hurricane-related at-risk children in the gulf coast states of Louisiana and Mississippi. 2007. https:// doi.org/10.7916/D8891FMF. Accessed 27 Dec. 2018.

5. Redlener I, Berman DA. Are American children primary targets of Al Qaeda terrorism? Implications for policy and preparedness planning. Prehosp Disaster Med. 2005;20(S1):s12. https://doi.org/10.1017/ S1049023X00012073Accessed 1 Jan. 2019.

6. Government Printing Office. Public Act 110-161 Consolidated Appropriations Act. 2008. https://www. govinfo.gov/content/pkg/PLAW-110publ161/pdf/ PLAW-110publ161.pdf. Accessed 1 Jan. 2019.

7. Federal Emergency Management Agency. A whole community approach to emergency management: principles, themes, and pathways for action. 2011. https://www.fema.gov/media-library-data/201307261813-25045-0649/whole_community_dec2011_2_. pdf. Accessed 1 Jan. 2019.

8. Federal Emergency Management Agency. Youth preparedness program. 2018. https://www.ready.gov/ youth-preparedness. Accessed 1 Jan. 2019.

9. Department of Health and Human Services. 20142015 Report of the Children's HHS Interagency Leadership on Disasters (CHILD) Working Group: Update on Department Activities. 2017. https://www.phe.gov/ Preparedness/planning/abc/Documents/child-20142015.pdf. Accessed 1 Jan. 2019.

10. Substance Abuse and Mental Health Services Administration. Disaster distress helpline. 2012. https://www. samhsa.gov/find-help/disaster-distress-helpline.

Accessed 1 Jan. 2019.

11. Department of Health and Human Services. TRACIE | Healthcare emergency preparedness information gateway. 2016. In: Asprtracie.hhs.gov. https://asprtracie. hhs.gov/. Accessed 1 Jan. 2019.

12. Department of Health and Human Services. Hospital preparedness program. 2018. https://www.phe.gov/ preparedness/planning/hpp/Pages/default.aspx. Accessed 7 Jan. 2019.

13. Department of Health and Human Services. National Advisory Committee on children and disasters. 2018. https://www.phe.gov/Preparedness/legal/boards/ naccd/Pages/default.aspx. Accessed 1 Jan. 2019. 
14. Department of Health and Human Services. Strategic national stockpile. 2018. www.phe.gov/about/sns. Accessed 21 Jan. 2019.

15. American Academy of Pediatrics. Medical countermeasures for children in public health emergencies, disasters, or terrorism. 2016. www.pediatrics. aappublications.org/content/137/2/e20154273. Accessed 21 Jan. 2019.

16. Federal Emergency Management Agency. The disaster declaration process. 2018. https://www.fema.gov/ disaster-declaration-process. Accessed 3 Jan. 2019.

17. Association of State and Territorial Health Officials. Key federal laws and policies regarding emergency authority and immunity. 2019. http://www.astho.org/ Programs/Preparedness/Public-Health-EmergencyLaw/Emergency-Authority-and-Immunity-Toolkit/ Key-Federal-Laws-and-Policies-Regarding-EmergencyAuthority-and-Immunity/. Accessed 3 Jan. 2019.

18. Department of Homeland Security. National response framework. 2014. https://www.fema.gov/media-library/ assets/documents/32230\#. Accessed 3 Jan. 2019.

19. Department of Homeland Security. What is NIMS? n.d. https://www.usda.gov/sites/default/files/documents/ NIMLesson.pdf. Accessed 3 Jan. 2019.

20. American Academy of Pediatrics. Family reunification following disasters: a planning tool for healthcare facilities. 2018. https://www.aap.org/en-us/Documents/ AAP-Reunification-Toolkit.pdf. Accessed 8 Jan. 2019.

21. Department of Health and Human Services. Emergency support functions. 2018. https://www.phe.gov/ preparedness/support/esf8/Pages/default.aspx. Accessed 3 Jan. 2019.

22. Department of Health and Human Services. Public health emergency declarations 2018. https://www.phe. gov/Preparedness/legal/Pages/phedeclaration.aspx. Accessed 3 Jan. 2019.

23. Federal Emergency Management Agency. The National Prevention Framework. n.d. https://www.fema.gov/ media-library-data/1466011024787-

91b8e49bf7344dd6dadca441c26272ad/

InformationSheet_Prevention_Framework.pdf.

Accessed 3 Jan. 2019.

24. Federal Emergency Management Agency. The National Recovery Framework. n.d. https://www.fema.gov/medialibrary-data/146601752826273651ed433ccfe080bed88014ac397cf/InformationSheet_ Recovery_Framework.pdf. Accessed 3 Jan 2019.

25.• Federal Emergency Management Agency. The National Response Framework. n.d. https://www.fema.gov/ media-library-data/14660148912816e7f60ceaf0be5a937ab2ed0eae0672d/ InformationSheet_Response_Framework.pdf.

Accessed 3 Jan 3 2019. The NRF is the keystone document that outlines the role that the federal government will play in the support of its partners during disaster response. It is very useful to understand the massive scope of federal disaster response and all of its moving parts.

26. Federal Emergency Management Agency. The national mitigation framework. n.d. https://www.fema.gov/ media-library-data/14660145524621b78d1a577324a66c4eb84b936c68f16/ InformationSheet_Mitigation_Framework.pdf. Accessed 4 Jan 2019.

27. Federal Emergency Management Agency. The national protection framework. n.d. https://www.fema.gov/ media-library-data/146601358716486696df20638bbf24e25d70070eda114/ InformationSheet_Protection_Framework.pdf. Accessed 3 Jan 2019.

28. Department of Homeland Security. The national preparedness goal. 2015. https://www.fema.gov/medialibrary-data/14437996151712aae90be55041740f97e8532fc680d40/National_ Preparedness_Goal_2nd_Edition.pdf. Accessed 3 Jan 2019

29. Hodge JG. Legal issues concerning volunteer health professionals and the hurricane-related emergencies in the gulf coast region. Public Health Rep. 2006;121(2):205-7. https://doi.org/10.1177/ 003335490612100217 Accessed 1 Jan 2019.

30. Federal Emergency Management Agency. Sixty percent of Americans not practicing for disaster. 2015. https:// www.fema.gov/news-release/2015/04/28/sixtypercent-americans-not-practicing-disaster-fema-urgeseveryone-prepare. Accessed 3 Jan 2019.

31. Centers for Medicare and Medicaid Services. Emergency preparedness rule. 2018. https://www.cms.gov/ medicare/provider-enrollment-and-certification/ surveycertemergprep/emergency-prep-rule.html.

Accessed 3 Jan 3 2019. For individuals working in the healthcare sector administration, understanding the CMS Preparedness Rule is critical- as it can impact federal reimbursement for patient care. The Rule requires that healthcare providers and suppliers be in compliance with certain emergency preparedness regulations, such as training and exercises.

32. National Volunteer Fire Council. Volunteer fire service fact sheet. n.d. https://www.nvfc.org/wp-content/ uploads/2016/02/NVFC-Fact-Sheet-2018.pdf.

Accessed 3 Jan. 2019.

33. Department of Health and Human Services. Join the National Disaster Medical System. 2018. https://www. phe.gov/Preparedness/responders/ndms/Pages/joinndms.aspx. Accessed 4 Jan 42019.

34. Team Rubicon. Team Rubicon Disaster Response. 2018. https://teamrubiconusa.org/volunteer/. Accessed 4 Jan. 2019.

35. International Medical Corps. Volunteer with IMC. 2017. https://careers.internationalmedicalcorps.org/ volunteer.html. Accessed 4 Jan. 2019.

36. American Academy of Pediatrics. Children and disasters: disaster preparedness to meet children's needs. 
2019. https://www.aap.org/en-us/advocacy-andpolicy/aap-health-initiatives/Children-and-Disasters/ Pages/default.aspx.

Accessed 7 Jan. 2019. The AAP is a longstanding active stakeholder in improving the care of children impacted by disaster. Their Disaster Preparedness Advisory Council (DPAC) is a national-level advocate for ensuring equity in preparedness for infants, children, and adolescents.

\section{Publisher's Note}

Springer Nature remains neutral with regard to jurisdictional claims in published maps and institutional affiliations. 